\title{
THE CALIBRATION PROCESS AND METROLOGICAL ANALYSIS OF A TRANSDUCER USED TO MEASURE TWO PHYSICAL QUANTITIES
}

\author{
Adam IDŹKOWSKI", Jerzy GOŁĘBIOWSKI*, Wojciech WALENDZIUK* \\ *Faculty of Electrical Engineering, Bialystok University of Technology, ul. Wiejska 45D, 15-351 Bialystok, Poland \\ a.idzkowski@pb.edu.pl, j.golebiowski@pb.edu.pl, w.walendziuk@pb.edu.pl
}

received 10 October 2016, revised 17 May 2017, accepted 19 May 2017

\begin{abstract}
This article presents a way of calibration of an unconventional two-current circuit, named $2 \mathrm{~J}+2 \mathrm{R}$, which consists of two current sources and two referential resistors connected to the circuit mass. This bridge was used to measure the beam deflection and the temperature increase simultaneously with the use of a pair of metal strain gauges. This paper contains theoretical and corrected (after calibration) processing characteristics of the measurement circuit. Calibration coefficients of both inputs, responsible for measurement of the measured values in the places where the strain gauges are attached, were calculated. Moreover, the standard combined and expanded uncertainties of both calibration coefficients were calculated and an uncertainty budget was made.
\end{abstract}

Key words: Measurement Systems, Calibration, Measurement Uncertainty, Strain Gauges, Temperature

\section{INTRODUCTION}

This article contains a description of a circuit used to measure the increase of two physical quantities simultaneously, e.g. the increase of a cantilever beam deflection and the increase of temperature. A double-output system of a two-current bridge $(2 \mathrm{~J}+2 \mathrm{R})$ was applied. The output voltages of this direct current bridge are functions of differences and sums of the resistance increases of two foil strain gauges attached to a cantilever beam. Such circuit can be an alternative for system solutions in the case when deflection and temperature need to be recorded in the same point of the measured element (Idzkowski et al., 2015; Cappa et al., 2001; Paker, 1993). Also other solutions can be treated as differential measurement circuits, e.g. a classic double bridge (Pedersen et al., 2005) or an impedance unbalanced bridge (Musiol et al., 2010).

All devices of this type need to be calibrated. The process of calibration can be conducted with the use of special equipment, e.g. additional resistors regulated in the bridge circuit (Surya et al., 2011), or through a microprocessor circuit which corrects numerically the function dependence between the output signal and the measured quantity.

In this article, a programming way (using a microprocessor circuit) of calibration is described. The aim of the device is to record continuously the changes of the beam deflections caused by the micrometer screw in a certain temperature range. The values of deflection and temperature changes are calculated on the basis of the calibration coefficients during data recording and given online on the computer screen. In order to determine the corrected values of the deflection and temperature changes, the values of output voltages obtained during calibration of the measurement device (for min. and max. deflection at constant temperature) and the voltage values measured online are needed.

Converting the output voltages into the measured values demanded determining the uncertainty. Therefore, the analysis of standard uncertainties (Joint Committee of Guides in Metrology, 2008) of calibration coefficients for both measure values was carried out.

\section{SENSORS AND A MEASUREMENT SYSTEM OF A DOUBLE-OUTPUT TRANSDUCER OF THE RESISTANCE AND VOLTAGE INCREASES OF SUM AND DIFFERENCE}

In order to conduct research concerning an unconventional circuit for simultaneous measurement of two physical quantities, a set of two foil strain gauges TF-3/120 (TENMEX, 2016) was used. The strain gauges have a linear characteristics average relative resistance increase $\varepsilon w$ in the function of the small of the beam deflection $X$ and its initial value $X_{\min }$

$\varepsilon_{W}=a_{d}\left(X-X_{\min }\right)+b_{d}$,

where: $a_{d}$-coefficient of the characteristics slope (in the analyzed case, the free word $b_{d}$, responsible for the offset error $\left(b_{d}=0\right)$ ), was rejected.

The relative temperature increase of resistance $\varepsilon_{T}$ for the strain gauges depends linearly on the difference of the temperature $T$ and its minimum value $T_{\min }$ (VISHAY Precision Group, 2007)

$\varepsilon_{T}=\alpha\left(T-T_{\min }\right)$.

Formula (2) contains the temperature coefficient of resistance $\alpha\left[1 /{ }^{\circ} \mathrm{C}\right]$. It represents the sum of two components: thermal expansion of the strain gauge mesh material (constantan) and the difference of the thermal expansion coefficients of the strain gauges and the material of the surface. The difference is multiplied by the deflection sensitivity coefficient of the strain gauges (VISHAY Precision Group, 2007).

The set of two strain gauges, mentioned above, was connected to an unconventional two-current bridge $2 J+2 R$ (Fig. 1) and 
a data acquisition mode (Fig. 2). The worked out measurement system allows to determine directly the values of the difference $\varepsilon_{1}-\varepsilon_{2}$ and the sum $\varepsilon_{1}+\varepsilon_{2}$ of the resistance relative increases $R_{1}$ and $R_{2}$. The equations in the function of the output voltages, assuming that $\varepsilon_{1}+\varepsilon_{2} \ll 1$, are presented below.

$\varepsilon_{W}=\frac{\left(\varepsilon_{1}-\varepsilon_{2}\right) W}{2}=\frac{2\left(U_{A B W} U_{A B W \min }\right)}{\bar{J} R_{0}}$,

$\varepsilon_{T}=\frac{\left(\varepsilon_{1}+\varepsilon_{2}\right) W}{2}=\frac{3\left(U_{D C W}-U_{D C W \min }\right)}{\bar{J} R_{0}}$,

where: $\quad U_{A B W}=W U_{A B}, \quad U_{D C W}=W U_{D C}, \quad U_{A B W \min }=W U_{A B \min }$, $U_{D C W \text { min }}=W U_{D C \text { min }}, W$ - voltage amplification coefficient of the amplifiers, $\bar{J}=\frac{J_{1}+J_{2}}{2}$ - current mean average of both current sources (LT3092) supplying the circuit, $R_{r 1}=R_{r 2}=R_{0}$. Equations (3) and (4) can be obtained by solving the system of equations for the circuit, presented in Fig. 1, with the nodal analysis, where $U_{A B}=V_{A^{-}} V_{B}, U_{D C}=V_{D^{-}} V_{C}$.

It is worth stressing that the current $\bar{J}$, which is the mean average of the currents of both sources, was determined by measuring the voltage decrease $\bar{U}_{R / 1}, \bar{U}_{R / 2}$ on $R_{/ 1}$ and $R_{\Omega}$ resistances. It can be therefore assumed that

$\bar{J}=0.5\left(\frac{\bar{U}_{R / 1}}{R_{/ 1}}+\frac{\bar{U}_{R / 2}}{R_{\Omega 2}}\right)$.

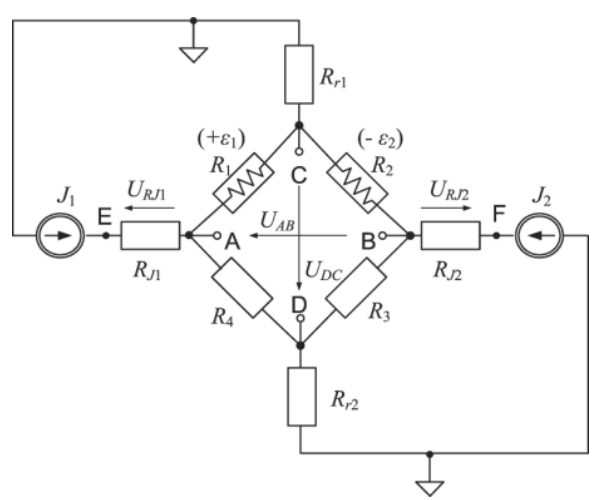

Fig. 1. Two-current bridge $(2 J+2 R)$

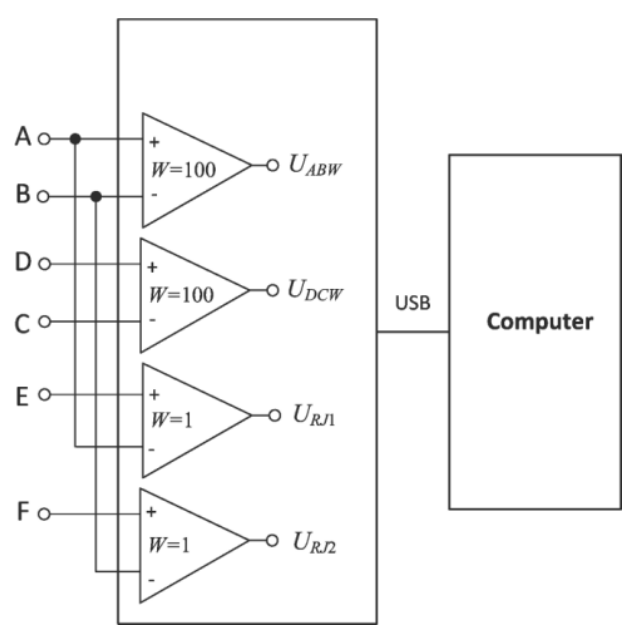

Fig. 2. LabJack data acquisition module with $A D 623 A$ amplifiers of $W$ amplification

It results from equations (3) and (4) that after attaching a strain gauge $R_{1}$ on the upper and the strain gauge $R_{2}$ on the lower surface of the beam, the voltage being the function of the beam deflection change can be obtained on one output of the system, and the voltage being function of the temperature change - on the opposite output.

\section{CHARACTERISTICS OF THE STRAIN GAUGE DEFLECTION AND TEMPERATURE CHANGES IN THE FUNCTION OF THE 2J+2R BRIDGE OUTPUT VOLTAGES}

Equations (1) and (2) were applied in formulas (3) and (4) respectively. The measured values of deflection change $\Delta X_{m}$ and temperature change $\Delta T_{m}$ can be then defined on the basis of average values of the bridge output voltages $\bar{U}_{A B W}, \bar{U}_{D C W}, \bar{U}_{A B W \min }, \bar{U}_{D C W \min }$ and current $\bar{J}$

$X-X_{\min }=\Delta X_{m}=\frac{2}{J R_{0} a_{d}}\left(\bar{U}_{A B W}-\bar{U}_{A B W \min }\right)=c_{1}\left(\bar{U}_{A B W}-\bar{U}_{A B W \min }\right),(6)$

$T-T_{\min }=\Delta T_{m}=\frac{3}{J R_{0} \alpha}\left(\bar{U}_{D C W}-\bar{U}_{D C W \min }\right)=e_{1}\left(\bar{U}_{D C W}-\bar{U}_{D C W \min }\right)$,

where: $c_{1}=\frac{2}{J R_{0 a_{d}}}, e_{1}=\frac{3}{J R_{0 \alpha}}$.

In the real circuit, the slope characteristics needs to be corrected. This was done through introducing $k_{1}$ and $k_{2}$ multipliers, which are further called calibration coefficients. The corrected values of the deflection changes $\Delta X_{p}$ and the temperature changes $\Delta T_{p}$ are products of calibration coefficients and the measured values $\Delta X_{m}$ and $\Delta T_{m}$, defined by formulas (6) and (7)

$\Delta X_{p}=k_{1} \Delta X_{m}$,

$\Delta T_{p}=k_{2} \Delta T_{m}$.

The way of determining multipliers $k_{1}$ and $k_{2}$ is discussed in the following section.

\section{COEFFICIENTS OF CALIBRATION AND VOLTAGE SENSITIVITY TO THE BEAM DEFLECTION AND TEMPERATURE INCREASES}

After substituting (6) into (8), the corrected value of the deflection change was obtained

$\Delta X_{p}=k_{1} c_{1}\left(\bar{U}_{A B W}-\bar{U}_{A B W \min }\right)$.

The graphic interpretation of equation (10) is presented in Fig. 3.

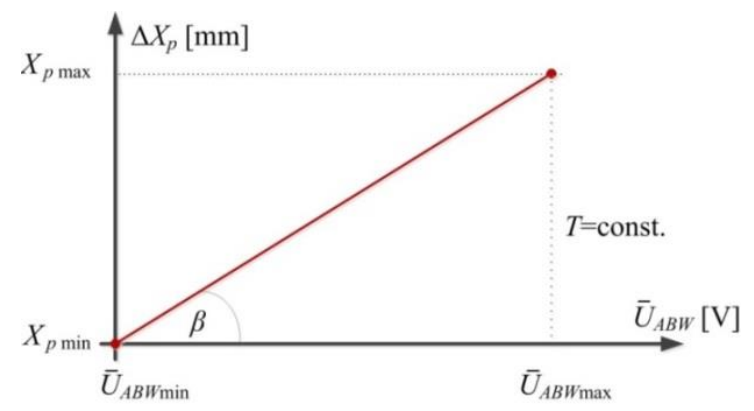

Fig. 3. The corrected characteristics of the beam deflection at constant temperature

Minimum and maximum $\bar{U}_{A B W \max }, \bar{U}_{A B W \text { min }}$ values are determined through measurements. Due to the rules of calibration, 
unknown corrected values $X_{p \max }, X_{p \min }$ were substituted by $X_{\min }$ and $X_{\max }$ reference values (Fig. 3). As it is known, the slope coefficient $(10)$ is also the tangent of the slope angle.

$k_{1} c_{1}=\tan \beta=\frac{X_{\max }-X_{\min }}{\bar{U}_{A B W \max }-\bar{U}_{A B W \min }}$.

After taking $c_{1}$ (as in (6)) into account, the coefficient of measurement calibration of deflection change at constant temperature was determined

$k_{1}=\frac{X_{\max }-X_{\min }}{\bar{U}_{A B W \max }-\bar{U}_{A B W \min }} \frac{\bar{J} R_{0} a_{d}}{2}=\frac{\Delta X}{\Delta \bar{U}_{A B W}} \frac{\bar{J} R_{0} a_{d}}{2}$.

The voltage sensitivity $U_{A B W}$ for $1 \mathrm{~mm}$ of the beam deflection results from formula (10)

$S_{X U}=\frac{1}{k_{1} c_{1}}=\frac{\Delta \bar{U}_{A B W}}{\Delta X}$.

After substituting (7) into (9), similarly, the coefficient of measurement calibration of temperature change at constant beam deflection was obtained

$k_{2}=\frac{T_{\max }-T_{\min }}{\bar{U}_{D C W \max }-\bar{U}_{D C W \min }} \frac{\bar{J} R_{0} \alpha}{3}=\frac{\Delta T}{\Delta \bar{U}_{D C W}} \frac{\bar{J} R_{0} \alpha}{3}$.

where: $T_{\max }$ and $T_{\min }$ are reference values. The coefficient of voltage sensitivity to temperature change of $1 \mathrm{~K}$ equals

$S_{T U}=\frac{\Delta \bar{U}_{D C W}}{\Delta T}$.

\subsection{Experimental Determining of the Temperature and Beam Deflection Increases and the K1 And K2 Calibration Coefficients}

The measured values $\Delta X_{m}$ and $\Delta T_{m}$ were determined on the basis of $U_{A B W}, U_{A B W \text { min }}, U_{D C W}, U_{D C W \text { min }}, U_{R / 1}, U_{R / 2}$ voltage records from the $2 \mathrm{~J}+2 \mathrm{R}$ bridge circuit with the use of the lab Jack UE-9Pro data acquisition system, in the way presented in Fig. 2. Two strain gauges attached on the upper and lower surfaces of the beam (as presented in Fig. 4) were included into the bridge circuit with the use of a screen wire.

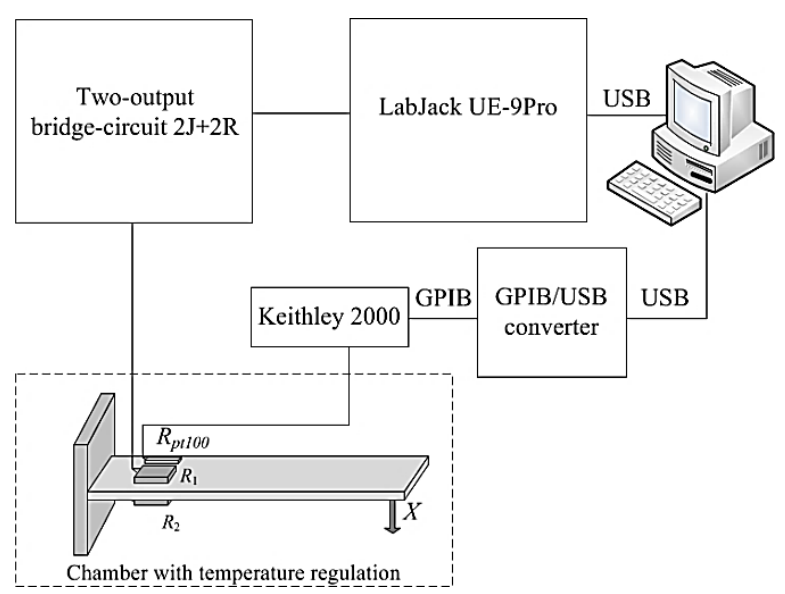

Fig. 4a. Laboratory stand consisting of a two-current bridge (2J+2R), a beam with attached strain gauges and a Pt100 sensor, a heating chamber with a thermostat, a LabJack measurement module, a Keithley 2000 multimeter and a computer

In order to determining the corrected values $\Delta X_{p}$ and $\Delta T_{p}$ it is vital to know the minimum and maximum reference deflection and reference temperature. Therefore, a platinum Pt100 RTD (class A) was attached on the upper surface of the beam, next to the strain gauge. The RTD was connected to a Keithley 2000 multimeter. The set of the platinum Pt100 RTD with a multimeter was used to set the $T_{\min }$ and $T_{\max }$ temperature values, required to calibrate the bridge, precisely.

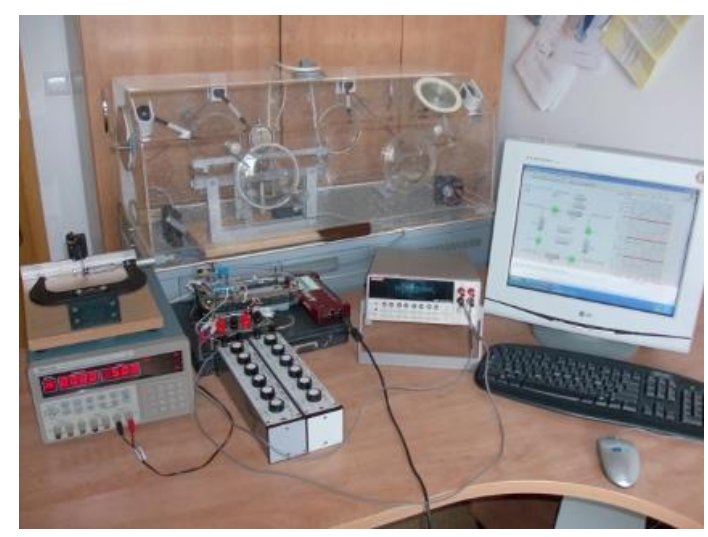

Fig. 4b. General view of the laboratory stand

The beam deflections were done with the use of a micrometer screw within the $\langle 0,10\rangle \mathrm{mm}$ range with the limiting error of $\pm 0.01 \mathrm{~mm}$. The mechanism deflecting the beam with attached strain gauges and the Pt100 sensor was placed in a heating chamber with a thermostat. This gave the experiment the temperature stability during the bridge calibration (in the range of $\pm 1^{\circ} \mathrm{C}$ ). It is crucial that all positions of deflection on the micrometer screw are performed at a selected, constant temperature.

Before the experiment, the temperature coefficient value of $\alpha$ resistance of the strain gauge attached to the beam was checked through measuring the resistance increases of the strain gauges at the temperature change from $22^{\circ} \mathrm{C}$ to $62^{\circ} \mathrm{C}$. The experimentally determined coefficient equalled 4.07 . $10^{-5}\left[1 /{ }^{\circ} \mathrm{C}\right]$. The manufacturer of the strain gauges gives the coefficient value of $4 \cdot 10^{-5}\left[1 /{ }^{\circ} \mathrm{C}\right]$ (for a measurement mesh of strain gauges made of constantan) (TENMEX, 2016). Due to the fact that the difference is insignificant, the value given by the manufacturer was taken in further calculations.

Connecting the temperature meter and the LabJack system to the computer with the use of the USB interface enabled simultaneous reading the voltage on the bridge and the adequate temperature in the chamber. The results recalculated with the use of a computer program (created in the LabVIEW environment) were recorded in a text file. The measurements were conducted at the following LabJack data acquisition system settings: 20 bits of the $\mathrm{A} / \mathrm{C}$ transducer resolution, $5 \mu \mathrm{V}$ voltage resolution of the measurement.

\subsection{Comparison of the Beam Deflection Values and the Temperature Changes Resulted from the Measurement Equations Before and after Calibration. Metrological Estimation of the Results Differences}

The measurement experiment aimed at comparing the values of deflection increases $\Delta X_{m}(6)$ and the temperature increases $\Delta T_{m}(7)$ obtained without calibration with the $\Delta X_{p}(8)$ and $\Delta T_{p}$ (9) values obtain as a result of calibration. Therefore, there was 
a necessity to determine the $k_{1}$ and $k_{2}$ calibration coefficients experimentally.

Tab. 1 and 2 present the measurement results of the bridge output voltages and the supplying current at the following temperatures: $T_{\min }=22{ }^{\circ} \mathrm{C}$ and $T_{\max }=62{ }^{\circ} \mathrm{C}$, for the beam deflections set with the use of the micrometric screw within the range of $\langle 0,10\rangle$ $\mathrm{mm}$ with the step of $1 \mathrm{~mm}$. Each value is the arithmetic mean of $N=200$ recorded samples.

Tab. 1. Voltage and current mean values for sensors at $T_{\min }=22{ }^{\circ} \mathrm{C}$ for subsequent beam deflection values

\begin{tabular}{|c|c|c|c|}
\hline $\boldsymbol{X}$ & $\begin{array}{c}\overline{\boldsymbol{U}}_{A B \boldsymbol{W}} \\
\left(\boldsymbol{T = \mathbf { 2 2 }}{ }^{\circ} \mathrm{C}\right)\end{array}$ & $\begin{array}{c}\overline{\boldsymbol{U}}_{\boldsymbol{D} \boldsymbol{D C W}} \\
\left(\boldsymbol{T = 2 2}{ }^{\circ} \mathbf{C}\right)\end{array}$ & $\overline{\boldsymbol{J}}$ \\
\hline $\mathrm{mm}$ & $\mu \mathrm{V}$ & $\mu \mathrm{V}$ & $\mu \mathrm{A}$ \\
\hline 0.00 & $-40867.3(\mathrm{~min})$ & 5060.9 & 10054.9 \\
\hline 1.00 & -35806.5 & 4743.0 & 10054.8 \\
\hline 2.00 & -33202.0 & 4239.9 & 10054.7 \\
\hline 3.00 & -28259.3 & 4257.0 & 10054.7 \\
\hline 4.00 & -24290.6 & 4142.8 & 10054.8 \\
\hline 5.00 & -19625.3 & 3994.8 & 10054.8 \\
\hline 6.00 & -14685.8 & 4014.4 & 10054.8 \\
\hline 7.00 & -8959.9 & 3764.7 & 10054.8 \\
\hline 8.00 & -6340.7 & 3357.4 & 10055.0 \\
\hline 9.00 & -2354.5 & 3373.3 & 10055.0 \\
\hline 10.00 & $1539.0(\max )$ & 3553.6 & 10055.2 \\
\hline
\end{tabular}

Tab. 2. Voltage and current mean values for sensors at $T_{\min }=62^{\circ} \mathrm{C}$ for subsequent beam deflection values

\begin{tabular}{|c|c|c|c|}
\hline $\boldsymbol{X}$ & $\begin{array}{c}\overline{\boldsymbol{U}}_{A B W} \\
\left(\boldsymbol{T = 6 2}{ }^{\circ} \mathrm{C}\right)\end{array}$ & $\begin{array}{c}\overline{\boldsymbol{U}}_{D C W} \\
\left(\boldsymbol{T = 6 2}{ }^{\circ} \mathrm{C}\right)\end{array}$ & $\bar{J}$ \\
\hline $\mathrm{mm}$ & $\mu \mathrm{V}$ & $\mu \mathrm{V}$ & $\mu \mathrm{A}$ \\
\hline 0.00 & $-51256.5(\mathrm{~min})$ & -94704.2 & 10054.3 \\
\hline 1.00 & -46244.4 & -94540.2 & 10054.3 \\
\hline 2.00 & -40514.1 & -95133.6 & 10054.2 \\
\hline 3.00 & -39103.7 & -94788.3 & 10054.5 \\
\hline 4.00 & -33479.8 & -95694.5 & 10054.4 \\
\hline 5.00 & -27306.3 & -95882.1 & 10054.3 \\
\hline 6.00 & -22926.6 & -96213.6 & 10054.2 \\
\hline 7.00 & -21209.7 & -97158.6 & 10054.6 \\
\hline 8.00 & -19232.6 & -97337.2 & 10054.6 \\
\hline 9.00 & -10317.2 & -96427.9 & 10054.3 \\
\hline 10.00 & $-5438.7(\mathrm{max})$ & -96257.5 & 10054.2 \\
\hline
\end{tabular}

The $k_{1}$ and $k_{2}$ calibration coefficients were calculated on the basis of (12) and (14). The results are given in Tab. 3 .

On the basis of the values included in Tab. 3, a change of the $k_{1}$ calibration coefficient value can be observable. The value of this coefficient is greater (of $8.05 \%$ ) for the lower temperature. In the case of the $k_{2}$ coefficient it can be assumed that the $X$ value, for which the calibration is carried out, is not important (the change in this case is only $0.05 \%$ ).

Tab. 3. Values of the $k_{1}$ and $k_{2}$ calibration coefficients

\begin{tabular}{|c|c|c|c|}
\hline & $\begin{array}{c}\text { Range of } X: \\
X_{\min }=0 \mathrm{~mm} \\
X_{\max }=10 \mathrm{~mm}\end{array}$ & & $\begin{array}{c}\text { Range of } T: \\
T_{\min }=22^{\circ} \mathrm{C} \\
\boldsymbol{T}_{\max }=62^{\circ} \mathrm{C}\end{array}$ \\
\cline { 2 - 2 } & $\boldsymbol{k}_{1}$ & & $\boldsymbol{k}_{2}$ \\
\hline$T=22^{\circ} \mathrm{C}$ & 1.20232 & $X=0 \mathrm{~mm}$ & 0.66182 \\
\hline$T=62^{\circ} \mathrm{C}$ & 1.11279 & $X=10 \mathrm{~mm}$ & 0.66152 \\
\hline
\end{tabular}

The following fixed values were assumed in order to conduct the calculations: $a_{d}=0.00832 \mathrm{~mm}^{-1}$ [2], $W=100, \alpha=0.00004^{\circ} \mathrm{C}^{-1}$, $R_{0}=121.116 \Omega$.

Tab. 4 and 5 , accept the $X$ values set on the screw (at two fixed temperatures $T_{\min }=22^{\circ} \mathrm{C}$ and $T_{\max }=62^{\circ} \mathrm{C}$ ), contain also the $\Delta X_{m}$ values - the beam deflection change calculated on the basis of the measurement equation (6), and $\Delta X_{p}$ - the corrected deflection change obtained from the equation (10).

Moreover, the $\Delta_{X m}=\Delta X_{m}-X$ and $\Delta_{X p}=\Delta X_{p}-X$ differences were calculated for both temperatures. The $\Delta_{X p}$ differences were related to the $\Delta X=X_{\max }-X_{\min }$ measurement range, calculating relative errors of the $\delta_{p 22}$ and $\delta_{p 62}$ determined deflection values.

Tab. 4. The $\Delta X_{m}$ values obtained on the basis of the measurement equation (6) and the $\Delta X_{p}$ values determined on the basis of the calibration function (10) at the $T_{\min }=22^{\circ} \mathrm{C}$ fixed temperature. The differences of the two values and the $X$ value set on the micrometric screw and the relative value of the determined deflection value

\begin{tabular}{|c|c|c|c|c|c|}
\hline$X$ & $\Delta X_{m}$ & $\Delta X_{p}$ & $\Delta X_{m}-X$ & $\Delta X_{p}-X$ & $\delta_{p 22}=\frac{\left(\Delta X_{p}-X\right) 100}{X_{\max }-X_{\min }}$ \\
\hline $\mathrm{mm}$ & $\mathrm{mm}$ & $\mathrm{mm}$ & $\mathrm{mm}$ & $\mathrm{mm}$ & $\%$ \\
\hline 0.00 & 0.00 & 0.00 & 0.00 & 0.00 & 0.00 \\
\hline 1.00 & 0.99 & 1.19 & -0.01 & 0.19 & 1.93 \\
\hline 2.00 & 1.50 & 1.81 & -0.50 & -0.19 & -1.92 \\
\hline 3.00 & 2.47 & 2.97 & -0.53 & -0.03 & -0.27 \\
\hline 4.00 & 3.25 & 3.91 & -0.75 & -0.09 & -0.91 \\
\hline 5.00 & 4.17 & 5.01 & -0.83 & 0.01 & 0.09 \\
\hline 6.00 & 5.14 & 6.17 & -0.86 & 0.17 & 1.74 \\
\hline 7.00 & 6.26 & 7.52 & -0.74 & 0.52 & 5.24 \\
\hline 8.00 & 6.77 & 8.14 & -1.23 & 0.14 & 1.42 \\
\hline 9.00 & 7.55 & 9.08 & -1.45 & 0.08 & 0.82 \\
\hline 10.00 & 8.32 & 10.00 & -1.68 & 0.00 & 0.00 \\
\hline
\end{tabular}

Tab. 5. The $\Delta X_{m}$ values obtained on the basis of the measurement equation (6) and the $\Delta X_{p}$ values determined on the basis of the calibration function (10) at the $T_{\min }=22^{\circ} \mathrm{C}$ fixed temperature. The differences of the two values and the $X$ value set on the micrometric screw and the relative value of the determined deflection value

\begin{tabular}{|c|c|c|c|c|c|}
\hline$X$ & $\Delta X_{m}$ & $\Delta X_{p}$ & $\Delta X_{m}-X$ & $\Delta X_{p}-X$ & $\delta_{p 62}=\frac{\left(\Delta X_{p}-X\right) 100}{X_{\max }-X_{\min }}$ \\
\hline $\mathrm{mm}$ & $\mathrm{mm}$ & $\mathrm{mm}$ & $\mathrm{mm}$ & $\mathrm{mm}$ & $\%$ \\
\hline 0.00 & 0.00 & 0.00 & 0.00 & 0.00 & 0.00 \\
\hline 1.00 & 0.98 & 1.09 & -0.02 & 0.09 & 0.94 \\
\hline 2.00 & 2.11 & 2.34 & 0.11 & 0.34 & 3.45 \\
\hline 3.00 & 2.38 & 2.65 & -0.62 & -0.35 & -3.48 \\
\hline 4.00 & 3.49 & 3.88 & -0.51 & -0.12 & -1.20 \\
\hline 5.00 & 4.70 & 5.23 & -0.30 & 0.23 & 2.27 \\
\hline 6.00 & 5.56 & 6.18 & -0.44 & 0.18 & 1.83 \\
\hline 7.00 & 5.89 & 6.56 & -1.11 & -0.44 & -4.42 \\
\hline 8.00 & 6.28 & 6.99 & -1.72 & -1.01 & -10.11 \\
\hline 9.00 & 8.03 & 8.94 & -0.97 & -0.06 & -0.65 \\
\hline 10.00 & 8.99 & 10.0 & -1.01 & 0.00 & 0.00 \\
\hline
\end{tabular}

Fig. 5 - 8 were done on the basis of the values from Tab. 4 and 5 . Moreover, the slope coefficients and the regression lines shifts were calculated: $\Delta \widehat{X}_{m}=m_{1} X+m_{2}$ (for $T_{\min }=22^{\circ} \mathrm{C}$ 
and $T_{\max }=62{ }^{\circ} \mathrm{C}$ ) and $\Delta \widehat{X}_{p}=p_{1} X+p_{2} \quad$ (for $\quad T_{\min }=22^{\circ} \mathrm{C}$ and $T_{\max }=62^{\circ} \mathrm{C}$ ).

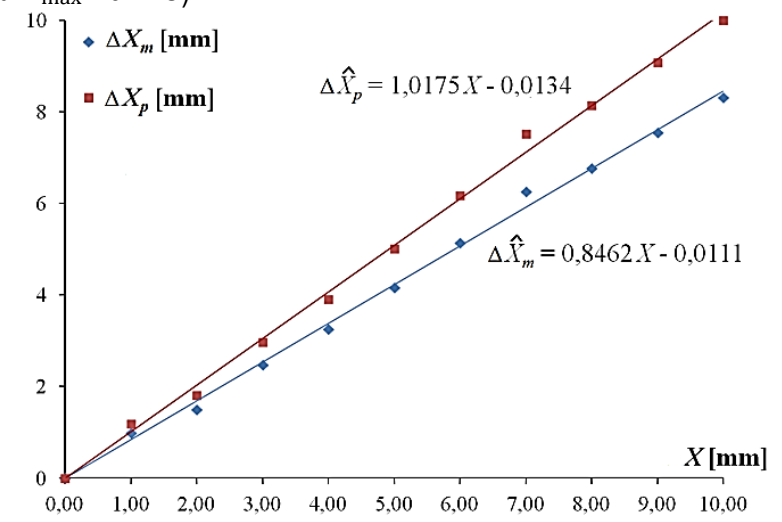

Fig. 5. Linear regression functions of the measured deflection change $\left(\Delta X_{m}\right)$ and the corrected deflection change $\left(\Delta X_{p}\right)$, depending on the $X$ deflection set on the screw (at $T_{\min }=22^{\circ} \mathrm{C}$ )

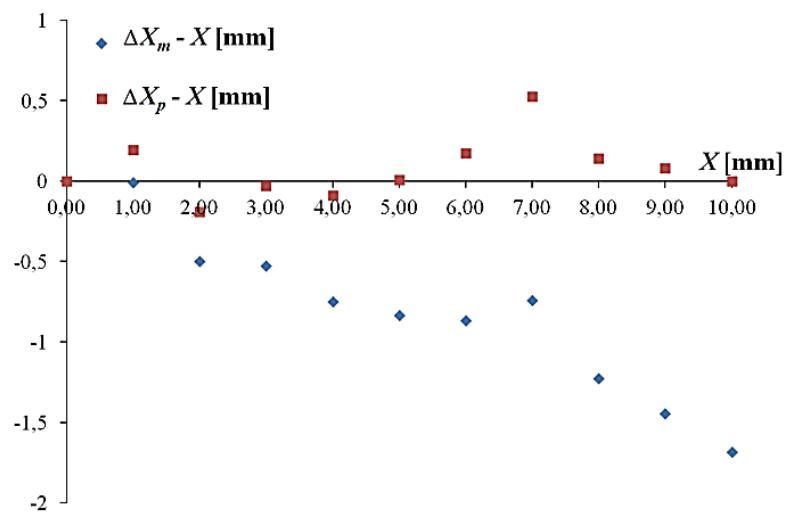

Fig. 6. The $\Delta X_{m}-X$ and $\Delta X_{p}-X$ differences (at $T_{\min }=22^{\circ} \mathrm{C}$ )

This can be seen in Fig. 5 and 7 that, due to the temperature increase from $T_{\min }$ to $T_{\max }$, the slope and lines shift coefficients change. However, the $p_{1}$ slope coefficient of the corrected regression lines are far closer to the ideal value (the value of one) than those of the lines which have not been corrected (without $\left.m_{1}\right)$. Fig. 6 and 8 show that, with very few exceptions, the $\mid \Delta X_{p}-$ $X \mid$ differences are smaller than $\left|\Delta X_{m}-X\right|$ at almost whole range of changes $\left\langle X_{\min }, X_{\max }\right\rangle$. Therefore, calibration has a positive influence on the measurement precision. The errors of the $\delta_{p T}$ determined deflection value related to the $\Delta X=X_{\max }-X_{\min }$ for both temperatures were assigned as: $\delta_{p 22}\left(T_{\min }=22^{\circ} \mathrm{C}\right)$ and $\delta_{p 62}\left(T_{\max }=62^{\circ} \mathrm{C}\right)$.

With some exceptions, the obtained $\left|\delta_{p 22}\right|$ values were smaller in comparison with $\left|\delta_{p 62}\right|$ values. This means that the calibration has better results in the lower temperature. The maximum relative error of the determined deflection value $\left|\delta_{p 62}\right|$ equals $10.11 \%$.

Tab. 6 contains the voltage coefficient of temperature sensitivity values $\left(S_{T U}\right)$ calculated on the basis of (15) for different values of $X$. The fixed mean value of $S_{T U}=-2496.9 \mu \mathrm{V} /{ }^{\circ} \mathrm{C} \approx-2.5 \mathrm{mV} /{ }^{\circ} \mathrm{C}$ was assumed within the range of $X \in\langle 0,10\rangle \mathrm{mm}$.

Tab. 7 compares the temperature change values $\Delta T_{m}$ (without calibration) and $\Delta T_{p}$ (after calibration) obtained as a result of applying equations (7), (9), (14) at constant deflection $X=0$ mm. Moreover, $\Delta_{T m}=\Delta T_{m}-\Delta T$ and $\Delta_{T p}=\Delta T_{p}-\Delta T$ for $X=0 \mathrm{~mm}$ were calculated. The $\Delta_{T p}$ differences in relation to the $T_{\max }-T_{\min }$ measurement range were determined by calculating the relative errors of the determined temperature change value $\delta_{T p}$.

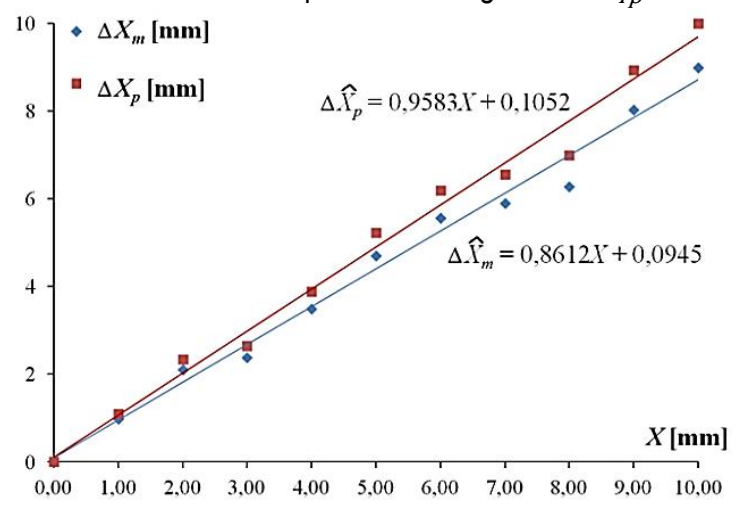

Fig. 7. Linear regression functions of the measured deflection change $\left(\Delta X_{m}\right)$ and the corrected deflection change $\left(\Delta X_{p}\right)$, depending on the $X$ deflection set on the screw (at $T_{\min }=62^{\circ} \mathrm{C}$ )

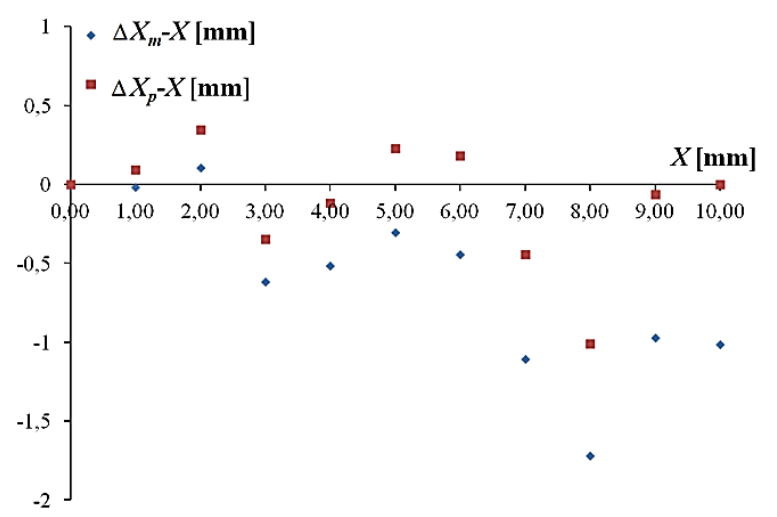

Fig. 8. The $\Delta X_{m}-X$ and $\Delta X_{p}-X$ differences (at $T_{\min }=62{ }^{\circ} \mathrm{C}$ )

Tab. 6. Voltage coefficient of temperature sensitivity $\left(S_{T U}\right)$ determined on the basis of the voltage measurement at two temperatures: $T_{\min }=22^{\circ} \mathrm{C}$ and $T_{\max }=62{ }^{\circ} \mathrm{C}$ for the $X$ value fixed with the use of a micrometric screw

\begin{tabular}{|c|c|c|c|}
\hline$X$ & $\bar{U}_{D C W \min }$ & $\bar{U}_{D C W \max }$ & $S_{T U}$ \\
\hline $\mathrm{mm}$ & $\mu \mathrm{V}$ & $\mu \mathrm{V}$ & $\mu \mathrm{V} /{ }^{\circ} \mathrm{C}$ \\
\hline 0.00 & 5060.9 & -94704.2 & -2494.1 \\
\hline 1.00 & 4743.0 & -94540.2 & -2482.1 \\
\hline 2.00 & 4239.9 & -95133.6 & -2484.3 \\
\hline 3.00 & 4257.0 & -94788.3 & -2476.1 \\
\hline 4.00 & 4142.8 & -95694.5 & -2495.9 \\
\hline 5.00 & 3994.8 & -95882.1 & -2496.9 \\
\hline 6.00 & 4014.4 & -96213.6 & -2505.7 \\
\hline 7.00 & 3764.7 & -97158.6 & -2523.1 \\
\hline 8.00 & 3357.4 & -97337.2 & -2517.4 \\
\hline 9.00 & 3373.3 & -96427.9 & -2495.0 \\
\hline 10.00 & 3553.6 & -96257.5 & -2495.3 \\
\hline
\end{tabular}

Also, linear regression functions $\Delta \widehat{T}_{m}=m_{3} \Delta T+m_{4}$ (for $X=$ $0 \mathrm{~mm}$ ) and $\Delta \widehat{T}_{p}=p_{3} \Delta T+p_{4}$ (for $X=0 \mathrm{~mm}$ ).are presented (Fig. 9). Fig. 10 shows differences between the values calculated from equations (7) or (9) and the reference value $\Delta T$. The maximum error value $\delta_{T p}$ (after calibration) was $1.71 \%$. 
Tab. 7. Temperature increase values $\left(\Delta T_{m}\right)$ obtained from (7) and $\Delta T_{p}$ values determined on the basis of the calibration function (9) for $T_{\min }=22^{\circ} \mathrm{C}$ and $T_{\max }=62{ }^{\circ} \mathrm{C}$ at fixed deflection $X=0 \mathrm{~mm}$. The differences $\Delta T_{m}=\Delta T_{m}-\Delta T, \Delta_{T p}=\Delta T_{p}-\Delta T$ and the relative error $\delta_{T p}\left(\Delta_{T p}\right.$ in relation to the $T_{\max }-T_{\min }$ changes)

\begin{tabular}{|c|c|c|c|c|c|c|}
\hline$\Delta T$ & $\bar{U}_{D C W}$ & $\overline{\Delta T_{m}}$ & $\Delta \bar{T}_{p}$ & $\Delta \bar{T}_{m}-\Delta T$ & $\Delta \bar{T}_{p}-\Delta T$ & \begin{tabular}{c}
$\delta_{T p}=$ \\
$\Delta_{T p} \mathbf{1 0 0}$ \\
\hline$T_{\max }-T_{\min }$
\end{tabular} \\
\hline${ }^{\circ} \mathrm{C}$ & $\mathrm{mV}$ & ${ }^{\circ} \mathrm{C}$ & ${ }^{\circ} \mathrm{C}$ & ${ }^{\circ} \mathrm{C}$ & ${ }^{\circ} \mathrm{C}$ & $\%$ \\
\hline 0 & 5.06 (min) & 0.0 & 0.00 & 0.00 & 0.00 & 0.00 \\
\hline 5 & -7.73 & 7.7 & 5.13 & 2.65 & 0.13 & 0.32 \\
\hline 10 & -20.70 & 15.4 & 10.33 & 5.42 & 0.33 & 0.82 \\
\hline 15 & -33.15 & 22.9 & 15.32 & 7.87 & 0.32 & 0.81 \\
\hline 20 & -45.74 & 30.4 & 20.37 & 10.41 & 0.37 & 0.92 \\
\hline 25 & -58.36 & 38.0 & 25.43 & 12.96 & 0.43 & 1.07 \\
\hline 30 & -70.81 & 45.4 & 30.42 & 15.41 & 0.42 & 1.05 \\
\hline 35 & -83.53 & 53.0 & 35.52 & 18.03 & 0.52 & 1.30 \\
\hline 40 & -96.41 (max) & 60.7 & 40.68 & 20.74 & 0.68 & 1.71 \\
\hline
\end{tabular}

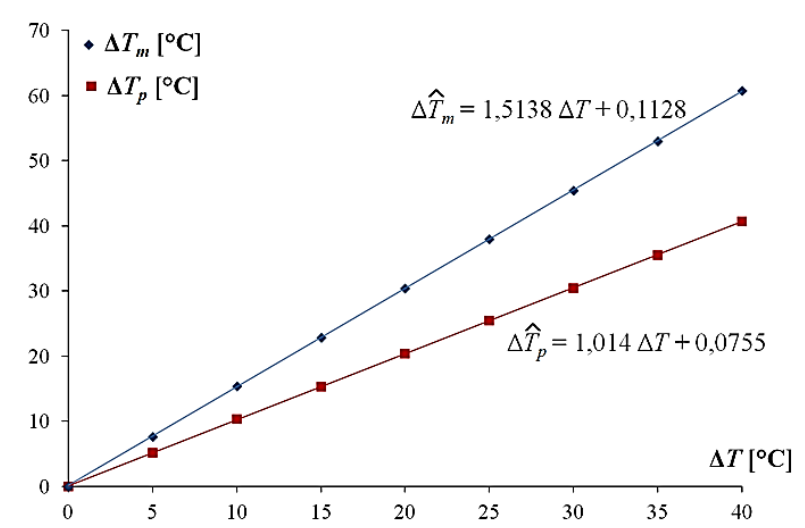

Fig. 9. Linear regression functions of the temperature increase $\Delta T_{m}$ and $\Delta T_{p}$ depended on the temperature increase $(\Delta T)$ set on the thermostat (at the deflection $X=0 \mathrm{~mm}$ )

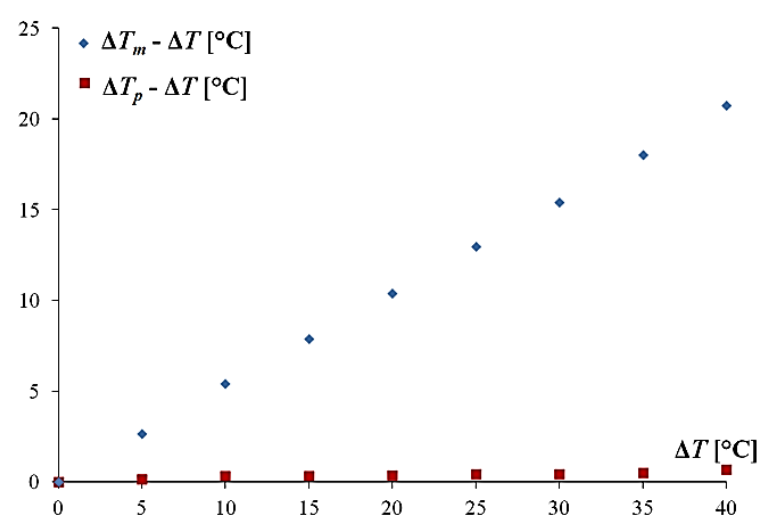

Fig. 10. The values of $\Delta \bar{T}_{m}-\Delta T$ and $\Delta \bar{T}_{p}-\Delta T$ differences for subsequent values of temperature increase $(\Delta T)$ set on the thermostat (at the deflection $X=0 \mathrm{~mm}$ )

Tab. 7 and Fig. 9, 10 clearly show that calibration increases significantly the precision of measurement.

\section{THE ANALYSIS OF THE K1 AND K2 CALIBRATION COEFFICIENTS UNCERTAINTY}

According to (7), the $k_{1}$ Calibration coefficient was calculated. Discussing the $k_{1}$ coefficient requires information concerning: the values of numerous quantities listed in Tab. 8 (in the first column), their uncertainties (three middle columns) and the assumed probability distribution (the last column). The measurement procedure for indirect measurements when the input quantities are not correlated was used.

The combined uncertainty was calculated from equation (16)

$u_{c}\left(k_{1}\right)=\sqrt{\begin{array}{c}\left(\frac{\partial k_{1}}{\partial \bar{J}}\right)^{2} \cdot u_{c}^{2}(\bar{J})+\left(\frac{\partial k_{1}}{\partial\left(\Delta \bar{U}_{A B W}\right)}\right)^{2} \cdot u_{c}^{2}\left(\Delta \bar{U}_{A B W}\right)+ \\ +\left(\frac{\partial k_{1}}{\partial(\Delta X)}\right)^{2} \cdot u_{c}^{2}(\Delta X)+\left(\frac{\partial k_{1}}{\partial R_{0}}\right)^{2} \cdot u_{c}^{2}\left(R_{0}\right)\end{array},}$,

where:

- the squared combined uncertainty of current measurement $\bar{J}$

$u_{c}^{2}(\bar{J})=\left(\frac{1}{2 R_{R 1}}\right)^{2} u^{2}\left(\bar{U}_{R / 1}\right)+\left(\frac{1}{2 R_{R 2}}\right)^{2} u^{2}\left(\bar{U}_{R / 2}\right)+$

$+\left(\frac{\bar{U}_{R / 1}}{2 R_{f 1}^{2}}\right)^{2} u^{2}\left(R_{/ 1}\right)+\left(\frac{\bar{U}_{R / 2}}{2 R_{\Omega 2}^{2}}\right)^{2} u^{2}\left(R_{/ 2}\right)$,

- the squared combined uncertainty of voltage difference measurement $\Delta \bar{U}_{A B W}$

$u_{c}^{2}\left(\Delta \bar{U}_{A B W}\right)=u^{2}\left(\bar{U}_{A B W \max }\right)+u^{2}\left(\bar{U}_{A B W \min }\right)$,

- the squared combined uncertainty of deflection difference measurement $\Delta X$

$u_{c}^{2}(\Delta X)=u^{2}\left(X_{\max }\right)+u^{2}\left(X_{\min }\right)$.

Tab. 9 contains the product of sensitivity coefficients (in the second power) and the combined uncertainties (in the second power, calculated on the basis of equations $(17-19))$. They are components (in the second power) of the combined uncertainty of the $k_{1}$ coefficient. Calculating a component related to the resistance dispersion $\left(R_{0}\right)$ was conducted with the assumption that the limiting error equals $\delta_{\text {grR } 0}= \pm 0.5 \%$ (estimated with the use of the exact differential).

The expanded uncertainty $U\left(k_{1}\right)$ was calculated with the assumption that the expansion coefficient $k_{p}=2$ and the confidence interval $p=0.95$

$U\left(k_{1}\right)=k_{p} \sqrt{u_{c}^{2}\left(k_{1}\right)}$

The complete result of the calculated $k_{1}$ coefficient (at $T=22^{\circ} \mathrm{C}$ )

$k_{1}=1.202 \pm 0.015$ for $k_{p}=2$ and $p=95 \%$.

The relative combined uncertainty $U_{w}\left(k_{1}\right)$ equals

$U_{w}\left(k_{1}\right)=\frac{U\left(k_{1}\right)}{k_{1}} 100 \%= \pm 1.25 \%$.

The limiting measurement error for the Pt100 sensor of class A equals $\pm(0.15+0.002 \cdot T)$. On this basis, the components of the $k_{2}$ combined uncertainty coefficient were calculated with the use of equations similar to (16)-(19), and presented in Tab. 10. 
Tab. 8. Uncertainty budget of the $k_{1}$ calibration coefficient: input quantities, their standard uncertainties and probability distribution

\begin{tabular}{|c|c|c|c|c|}
\hline $\begin{array}{c}\text { Measurement } \\
\text { quantities symbol } \\
\left(x_{i}\right) \\
\end{array}$ & $\begin{array}{c}\text { Uncertainty } \\
\text { of } A \text { type } \\
u_{A}\left(x_{i}\right) \\
\end{array}$ & $\begin{array}{c}\text { Uncertainty } \\
\text { of } B \text { type } \\
u_{\mathrm{B}}\left(x_{i}\right) \\
\end{array}$ & $\begin{array}{l}\text { Combined standard } \\
\text { uncertainty } u\left(x_{i}\right)\end{array}$ & $\begin{array}{l}\text { Type of probability distri- } \\
\text { bution }\end{array}$ \\
\hline$U_{R / 1}$ & $\sqrt{\frac{\sum_{k=1}^{N}\left(U_{R / 1}-\bar{U}_{R / 1}\right)^{2}}{N(N-1)}}$ & $\frac{\Delta_{g r U}}{\sqrt{3}}$ & $\sqrt{u_{A}^{2}\left(U_{R / 1}\right)+u_{B}^{2}\left(U_{R / 1}\right)}$ & $\begin{array}{l}\text { convolution of normal and } \\
\text { continuous uniform } \\
\text { distribution }\end{array}$ \\
\hline$R_{1}$ & - & $\frac{\Delta_{g r R J}}{\sqrt{3}}$ & $u_{B}\left(R_{f 1}\right)$ & $\begin{array}{l}\text { continuous uniform } \\
\text { distribution }\end{array}$ \\
\hline$U_{R / 2}$ & $\sqrt{\frac{\sum_{k=1}^{N}\left(U_{R / 2}-\bar{U}_{R / 2}\right)^{2}}{N(N-1)}}$ & $\frac{\Delta_{g r U}}{\sqrt{3}}$ & $\sqrt{u_{A}^{2}\left(U_{R / 2}\right)+u_{B}^{2}\left(U_{R / 2}\right)}$ & $\begin{array}{c}\text { convolution of normal and } \\
\text { continuous uniform } \\
\text { distribution }\end{array}$ \\
\hline$R_{J 2}$ & - & $\frac{\Delta_{g r R J}}{\sqrt{3}}$ & $u_{B}\left(R_{/ 2}\right)$ & $\begin{array}{l}\text { continuous uniform } \\
\text { distribution }\end{array}$ \\
\hline$U_{A B W \max }$ & $\sqrt{\frac{\sum_{k=1}^{N}\left(U_{A B W \max _{k}}-\bar{U}_{A B W \max }\right)^{2}}{N(N-1)}}$ & $\frac{\Delta_{g r U}}{\sqrt{3}}$ & $\sqrt{u_{A}^{2}\left(U_{A B W \max }\right)+u_{B}^{2}\left(U_{A B W \max }\right)}$ & $\begin{array}{c}\text { convolution of normal and } \\
\text { continuous uniform } \\
\text { distribution }\end{array}$ \\
\hline$U_{A B W \min }$ & $\sqrt{\frac{\sum_{k=1}^{N}\left(U_{A B W \min _{k}}-\bar{U}_{A B W \min }\right)^{2}}{N(N-1)}}$ & $\frac{\Delta_{g r U}}{\sqrt{3}}$ & $\sqrt{u_{A}^{2}\left(U_{A B W \min }\right)+u_{B}^{2}\left(U_{A B W \min }\right)}$ & $\begin{array}{l}\text { convolution of normal and } \\
\text { continuous uniform } \\
\text { distribution }\end{array}$ \\
\hline$R_{0}$ & - & $\frac{\Delta_{g r R 0}}{\sqrt{3}}$ & $u_{B}\left(R_{0}\right)$ & $\begin{array}{l}\text { continuous uniform } \\
\text { distribution }\end{array}$ \\
\hline$X_{\max }$ & - & $\frac{\Delta_{g r X}}{\sqrt{3}}$ & $u_{B}\left(X_{\max }\right)$ & $\begin{array}{l}\text { continuous uniform } \\
\text { distribution }\end{array}$ \\
\hline$X_{\min }$ & - & $\frac{\Delta_{g r X}}{\sqrt{3}}$ & $u_{B}\left(X_{\min }\right)$ & $\begin{array}{l}\text { continuous uniform } \\
\text { distribution }\end{array}$ \\
\hline
\end{tabular}

The following symbols were assumed: $\Delta_{g r U}$ - limiting error of the voltage measurement conducted with a LabJack module $( \pm 250 \mu \mathrm{V}), \Delta_{g r R J}-$ resistance limiting error $R_{/ 1}=R_{/ 2}=22 \Omega( \pm 0.22 \Omega), \Delta_{g r R 0}$ - resistance limiting error $R_{0}=121.116 \Omega( \pm 0.6 \Omega), \Delta_{g r X}$ - limiting error of the $X$ deflection measurement conducted with a micrometer screw $( \pm 0.01 \mathrm{~mm})$.

Tab. 9. Squared combined uncertainty components of the $k_{1}$ and their sum.

\begin{tabular}{|c|c|c|c|c|}
\hline$\left(\frac{\partial k_{1}}{\partial \bar{J}}\right)^{2} \cdot u_{c}^{2} \overline{(\bar{\jmath})}$ & $\left(\frac{\partial k_{1}}{\partial\left(\Delta \bar{U}_{A B W}\right)}\right)^{2} \cdot u_{c}^{2}\left(\Delta \bar{U}_{A B W}\right)$ & $\left(\frac{\partial k_{1}}{\partial(\Delta X)}\right)^{2} \cdot u_{c}^{2}(\Delta X)$ & $\left(\frac{\partial k_{1}}{\partial R_{0}}\right)^{2} \cdot u_{c}^{2}\left(R_{0}\right)$ & $u_{c}^{2}\left(k_{1}\right)$ \\
\hline 0.000024 & 0.000033 & 0.000001 & 0.000001 & 0.000059 \\
\hline
\end{tabular}

Tab. 10. Squared combined uncertainty components of the $k_{2}$ and their sum.

\begin{tabular}{|c|c|c|c|c|}
\hline$\left.\left(\frac{\partial k_{2}}{\partial \bar{J}}\right)^{2} \cdot u_{c}^{2} \bar{\emptyset}\right)$ & $\left(\frac{\partial k_{2}}{\partial\left(\Delta \bar{U}_{D C W}\right)}\right)^{2} \cdot u_{c}^{2}\left(\Delta \bar{U}_{D C W}\right)$ & $\left(\frac{\partial k_{2}}{\partial(\Delta T)}\right)^{2} \cdot u_{c}^{2}(\Delta T)$ & $\left(\frac{\partial k_{2}}{\partial R_{0}}\right)^{2} \cdot u_{c}^{2}\left(R_{0}\right)$ & $u_{c}^{2}\left(k_{2}\right)$ \\
\hline 0.000059 & 0.000002 & 0.000010 & 0.000001 & 0.000072 \\
\hline
\end{tabular}

The $k_{2}$ coefficient was determined on the basis of the data from tab. 10, with consideration of the expanded uncertainty

$k_{2}=0.662 \pm 0.017$ for $k_{p}=2$ and $p=95 \%$.

The relative expanded uncertainty $U_{w}\left(k_{2}\right)$ equals

$U_{w}\left(k_{2}\right)=\frac{U\left(k_{2}\right)}{k_{2}} 100 \%= \pm 2.56 \%$.
Relative uncertainty values of the expanded calibration coefficients are less than $5 \%$.

\section{CONCLUSIONS}

An example of a direct current bridge $(2 J+2 R)$ with two foil strain gauge sensors stuck on a cantilever beam application 
is described. The discussed circuit is a transducer of two quantities, i.e. the beam deflection change and the temperature change into two analogue DC voltages. The measurement equations (6) and (7) were applied for the tested circuit. After taking the described assumptions into account, the deflection and temperature changes are proportional towards the appropriate output voltage. The obtained results (Tab. 4 - column 2, Tab. 5 - column 2, Tab. 7 - column 3 ) required calibration. Calibration coefficients $\left(k_{1}\right.$ and $k_{2}$ ) were calculated from equations (12) and (14). The value and precision of determining those coefficients influence significantly the beam deflection and the temperature change obtained during measurements. It results from the values presented in Tab. 3 that determining the precise value of the $k_{1}$ is more difficult because its values obtained at $T_{\min }$ and $T_{\max }$ are different of $8.05 \%$. This probably results from the current drift of the supplies used to construct the bridge and its influence on the measured voltage $U_{A B}$. In the case of the $k_{2}$ coefficient the values determined for $T_{\min }$ and $T_{\max }$ differ only of $0.05 \%$. For the purpose of calculations, the fixed voltage coefficient of temperature sensitivity $S_{T U}$ (15) was assumed within the tested range of the beam deflection, i.e. $S_{T U} \approx-2.5 \mathrm{mV} /{ }^{\circ} \mathrm{C}$ for $X \in\langle 0,10\rangle \mathrm{mm}$.

Equations (8) and (9) describe the values of the beam deflection and temperature change after calibration. The appropriate results are Included in Tab, 4 - column 3, Tab. 5 - column 3 and Tab. 7 - column 4.

Relative errors (Tab 4, 5 and 7 - the last columns), which are the differences between the set and calibrated (with the use of a micrometric screw and a thermal chamber) bridge values related to the measurement ranges of both quantities, were calculated. The maximum relative errors of the determined value of deflection equalled: $\left|\delta_{p 22}\right|=5.24 \%$ (calibration conducted at $22^{\circ} \mathrm{C}$ ), $\left|\delta_{p 62}\right|=10.11 \%$ (calibration conducted at $62^{\circ} \mathrm{C}$ ). The maximum relative error of the determined value of the temperature change equalled $\left|\delta_{T p}\right|=1.71 \%$ (calibration for $X=0 \mathrm{~mm}$ ).

Additionally, the combined standard uncertainties of the $k_{1}$ and $k_{2}$ calibration coefficients were determined. The so called "uncertainty budget" was formulated (Tab. 8 - 10). Satisfactory values of relative extended uncertainties $U_{W}\left(k_{1}\right)= \pm 1.25 \%$, $U_{w}\left(k_{2}\right)= \pm 2.56 \%$ for the expansion coefficient $k_{p}=2$ and the confidence level $p=95 \%$ were obtained.

The presented experiments and calculations contribute to the development of alternative circuits applied to simultaneous measurement of a few physical quantities. They may be an interesting and valuable complement of well-known devices conditioning analogue signals (Kalita et al., 2015; Proto et al., 2016, Swartz et al., 2004). The ways of compensating the temperature influence in the inseparable structures of the Wheatstone's bridges (e.g. in the integrated pressure transducers) can be an example INTERSIL (2005), MAXIM Integrated Products Inc. (2002), Mozek et al., (2008). In solutions of this type, an additional temperature sensor, resistors or resistance temperature detectors circuits for compensating e.g. pressure piezoresistive silicon sensors of the X-ducer type, Motorola, are frequently applied (Swartz et al., 2004).

\section{REFERENCES}

1. Cappa P., Marinozzi F., Sciuto S.A. (2001), A Novel method for the simultaneous measurement of temperature and strain using a threewire connection, Measurement Science and Technology, 12(4), 502506.

2. Idzkowski A., Walendziuk W., Warsza Z.L. (2015), Unconventional double-current crcuit for deflection and temperature simultaneous measurement, Elektronika ir Elektrotechnika, 21(1), 23-27.

3. INTERSIL (2005), Sensor circuits and digitally controlled potentiometers, application note AN135.

4. JCGM - Joint Committee of Guides in Metrology (2008), Evaluation of measurement data - guide to the expression of uncertainty in measurement.

5. Kalita K., Das N., Boruah P.K., Sarma U. (2016), Design and uncertainty evaluation of a strain measurement system, MAPAN Journal of Metrology Society of India, 31(1), 17-24.

6. MAXIM Integrated Products Inc. (2002), Sensor temperature compensation using the four DAC signal conditioning architecture, application note 1839 .

7. Mozek M., Vrtacnik, D., Resnik D., Aljancic U., Penic S., Amon S. (2008), Digital self-learning calibration system for smart sensors, Sensors \& Actuators: A. Physical 141(1), 101-108.

8. Musiol K., Met A., Skubis T. (2010), Automatic bridge for comparison of inductance standards, Measurement, 43(10), 1661-1667.

9. Nudzikova, P., Slanina, Z. (2016), User identification by biometric methods, Intelligent Systems for Computer Modelling - Advances in Intelligent Systems and Computing, 423, 181-190.

10. Parker A.R. (1993), Simultaneous measurement of temperature and strain using four connecting wires, NASA Technical Memorandum 104271.

11. Pedersen C., Jespersen S.T., Krog J.P., Christensen C., Thomsen E.V. (2005), Combined differential and static pressure sensor based on a double-bridged structure, IEEE Sensors Journal 5 (3), 446- 454.

12. Proto A., Penhaker M., Bibbo D., Vala D., Conforto S., Schmid M. (2016), Measurements of generated energy/electrical quantities from locomotion activities using piezoelectric wearable sensors for body motion energy harvesting, Sensors ,16(4), 524.

13. Surya S., Nag S., Fernandes A.J., Gandhi S., Agarwal D., Chatterjee G., Ramgopal Rao V. (2011), Highly sensitive $\Delta R / R$ measurement system for nano-electro-mechanical cantilever based biosensors, International Symposium on Electronic System Design (ISED), 34- 38.

14. Swartz C., Derrington C., Gragg J. (2004), Temperature compensation methods for the Motorola X-ducer pressure sensor element, Motorola Semiconductor application notes AN840.

15. TENMEX (2016), strain gauges producer webpage, http://www.tenmex.pl.

16. VISHAY Precision Group (2007), Measurement of thermal expansion coefficient using strain gages, technical note TN-513-1, http://www.vishaypg.com/docs/11063/tn5131tn.pdf.

Acknowledgement: The paper was prepared at Bialystok University of Technology within a framework of the S/WE/1/2013 project sponsored by Ministry of Science and Higher Education. 